\title{
Effects of moxibustion on gastrointestinal function recovery in preventing early postoperative small-bowel obstruction: a meta-analysis
}

\author{
Lili Yang ${ }^{1,2 \#} \wedge$ Zhengjun $\mathrm{Li}^{3,4 \#}$, Wenlin $\mathrm{Li}^{2} \wedge, \mathrm{Li}_{\text {Zeng }}{ }^{1,2} \wedge$, Yaoyao Bian ${ }^{5} \wedge$ \\ ${ }^{1}$ School of First Clinical Medicine, Nanjing University of Chinese Medicine, Nanjing, China; ${ }^{2}$ Jingwen Library, Nanjing University of Chinese \\ Medicine, Nanjing, China; ${ }^{3}$ College of Health Economics Management, Nanjing University of Chinese Medicine, Nanjing, China; ${ }^{4}$ School of \\ Management, University of St Andrews, St Andrews, UK; ${ }^{5}$ School of Nursing, Nanjing University of Chinese Medicine, Nanjing, China \\ Contributions: (I) Conception and design: Y Bian, L Zeng; (II) Administrative support: L Yang, Y Bian; (III) Provision of study materials or patients: L \\ Yang, Z Li, Y Bian; (IV) Collection and assembly of data: Z Li, W Li; (V) Data analysis and interpretation: L Yang, Y Bian, L Zeng; (VI) Manuscript \\ writing: All authors; (VII) Final approval of manuscript: All authors. \\ "These authors contributed equally to this work. \\ Correspondence to: Prof. Yaoyao Bian, PhD. School of Nursing, Nanjing University of Chinese Medicine, 138 Xianlin Rd, Nanjing 210023 , China. \\ Email: bian@njucm.edu.cn; Prof. Li Zeng, PhD. School of First Clinical Medicine and Jingwen Library, Nanjing University of Chinese Medicine, \\ 138 Xianlin Rd, Nanjing 210023, China. Email: zengbingli@njucm.edu.cn.
}

\begin{abstract}
Background: Moxibustion is widely used in the recovery of gastrointestinal function in East Asian countries, especially in China. This systematic review aims to evaluate the recovery effects of moxibustion on gastrointestinal function in preventing early postoperative small-bowel obstruction (EPSBO).

Methods: The Medline, Embase, PubMed, and the other seven databases were searched independently by two authors. Randomized controlled trials (RCTs) were selected using the PICOS method. The methodological quality was appraised with the Cochrane's risk of bias tool, and the reporting quality of included studies was evaluated by Consolidated Standards of Reporting Trials (CONSORT) and STandards for Reporting Interventions in Clinical Trials of Moxibustion (STRICTOM), respectively. Revman 5.2.0 was used for statistical analysis, and the mean difference (MD) with 95\% confidence interval (CI) was performed for effect estimation. Random effects model (REM) and fixed effects model (FEM) were used for pooling data.

Results: A total of 8 RCTs with 693 participants were included. Meta-analysis showed that moxibustion combined with usual care had favorable effects on the time to first flatus (MD $-15.15 \mathrm{~h}, 95 \% \mathrm{CI}:-19.14$ to $-11.15,8$ studies, $\mathrm{I}^{2}=85 \%, \mathrm{P}<0.00001$, REM), the time to bowel sound recovery $(\mathrm{MD}-10.35 \mathrm{~h}, 95 \% \mathrm{CI}$ : -11.65 to $-9.06,7$ studies, $\mathrm{I}^{2}=0 \%, \mathrm{P}=0.91, \mathrm{FEM}$ ), the time to first defecation (MD $-18.94 \mathrm{~h}, 95 \% \mathrm{CI}:-24.53$ to $-13.36,3$ studies, $\left.\mathrm{I}^{2}=45 \%, \mathrm{P}=0.16, \mathrm{FEM}\right)$, and the duration time to abdominal distention $(\mathrm{MD}-11.7 \mathrm{~h}$, $95 \%$ CI: -15.32 to $-8.09,3$ studies, $\left.\mathrm{I}^{2}=0 \%, \mathrm{P}=0.70, \mathrm{FEM}\right)$ when compared to the controls. No adverse events were reported in the included studies.

Conclusions: Moxibustion may have a beneficial effect on the recovery of gastrointestinal function in preventing EPSBO. However, positive findings should be treated carefully. And rigorous studies with high quality and large samples are warranted.
\end{abstract}

Keywords: Moxibustion; recovery of gastrointestinal function; early postoperative small bowel obstruction; metaanalysis

^ ORCID: Lili Yang, 0000-0001-5220-3094; Zhengjun Li, 0000-0001-8208-3898; Wenlin Li, 0000-0002-7105-2743; Yaoyao Bian, 00000002-9968-2501; Li Zeng, 0000-0002-9095-9439. 
Submitted Jun 15, 2020. Accepted for publication Jan 15, 2021.

doi: 10.21037/apm-20-1266

View this article at: http://dx.doi.org/10.21037/apm-20-1266

\section{Introduction}

Early postoperative small bowel obstruction (EPSBO) is a normal response to tissue injury that occurs within two weeks after abdominal surgeries $(1,2)$. It is usually related to the dysfunction of gastrointestinal motility (3). Patients with small-bowel obstruction often cannot eat, pass flatus, or defecate within five days after a laparotomy or minimally invasive surgery (4). Its clinical features include abdominal pain, vomit, abdominal distension, dyschezia, and radiographic confirmation (5). It is reported that the incidence rates of EPSBO ranged from $0.69 \%$ in 1987 (6) to $9.5 \%$ in 2002 (1). And it is estimated that the mortality rates widely ranged from $2.4 \%$ to $15 \%$ (7-9).

Pickleman et al. (10) suggested that EPSBO is caused by adhesion, inflammation, and that non-operative therapy should be treated first. Currently, effective prevention and treatment is nasogastric decompression (11). If EPSBO is not resolved, eventual re-operation will be needed. It is not easy to find obstruction sites. And the re-operation can also cause intestinal injury and expand the extent of the operation, thereby resulting in postoperative bleeding, infection, intestinal fistula, and other complications. Moreover, it may reoccur or aggravate bowel obstruction. It not only extends hospitalization (12) and increases costs (13), but also creates discomfort and increases related postoperative complications (e.g., pulmonary complications) $(14,15)$. Therefore, early prevention and treatment of EPSBO are essential.

Thus far, complementary, and alternative therapies, especially Chinese therapy represented by moxibustion, have gained more and more attention from researchers due to their significant therapeutic potency in preventing and treating diseases. Moxibustion (moxa) is a kind of traditional oriental medicine, which originated from the meridian-collateral theory of traditional Chinese medicine (TCM). It has been used in East Asian medicine for more than a thousand years (16). It is a type of thermal therapy that stimulates specific acupoints through healing. This therapy is generated by burning dried herbs called mugwort leaves (Artemisia vulgaris). Moxibustion is widely accepted in East Asian countries, as well as throughout the world. Increasing evidence indicates that it can unblock the meridians and collaterals, and regulate the $q i$ and blood function of the spleen and stomach (17), thereby preventing nausea and vomiting (18), improving dyschezia and other main gastrointestinal symptoms (19). As the study reported that moxibustion could improve intestinal motility (20), indicating a potential method in preventing EPSBO. However, insufficient evidence is still lacking to reach a conclusion on this issue.

Herein, this systematic review aims to increase the existing level of evidence by evaluating the critical effects of moxibustion on preventing EPSBO. To our knowledge, this is the first meta-analysis using randomized controlled trials (RCTs) to review the gastrointestinal outcomes on this subject. We presented the following study in accordance with the Preferred Reporting Items for Systematic Reviews and Meta-Analyses (PRISMA) reporting checklist (available at http://dx.doi.org/10.21037/apm-20-1266).

\section{Methods}

\section{Search strategy}

A total of 10 electronic databases ranging from their inception dates to April 30, 2019, i.e., Cochrane Central Register of Controlled Trials, Manual, Alternative and Natural Therapy Index System, Allied and Complementary Medicine Database (AMED), PubMed, Embase, Medline, and four Chinese medicine databases, including China National Knowledge Infrastructure (CNKI) Database, Wanfang database, Chinese Science and Technology Periodical Database (VIP), and Chinese Biomedical Database (CBM) were searched, as well as databases that contained relevant ongoing trials, such as US equivalent clinical trial registry (http://www.clinicaltrials.gov). The search language was restricted to English and Chinese. The keywords used to search for RCTs were: "moxibustion" OR "moxibustion therapy" OR "moxa-moxibustion" OR "warm-moxibustion" OR "complementary therapies" OR "Chinese medicine" OR "traditional medicine" OR "alternative medicine" OR "complementary medicine" AND "postoperative small-bowel obstruction" OR "postoperative ileus" OR "EPSBO" OR "gastrointestinal function recovery" OR "gastrointestinal disorder" AND 
"randomiz". All eligible studies were reviewed, and all relevant data were identified by two review authors (L Yang and Y Bian). Any unresolved disagreements were discussed with a third review author $(\mathrm{Z} \mathrm{Li})$.

\section{Inclusion criteria}

Studies that met the PICOS (population, intervention, comparator, outcome, study type) criteria were included: (I) participants: patients regardless of age, gender, original disease, or type of surgery and anesthesia, who underwent abdominal or gastrointestinal surgery without experiencing postoperative small-bowel obstruction or any complications; (II) interventions: moxibustion at the acupoints alone or moxibustion combined with usual care; (III) comparators: usual care, e.g., fasting, gastrointestinal decompression, postoperative early mobilization and parenteral nutrition support; (IV) outcomes: the time to first flatus, the time to bowel sound recovery, the time to first defecation, and the duration time of abdominal distention. Bowel sounds were recorded at four quadrants of the abdomen with a standard interval (often every $2 \mathrm{~h}$ ) after operation; and (V) study type: RCTs.

\section{Exclusion criteria}

Studies that met the following criteria were excluded: (I) quasi-RCTs and non-RCTs; (II) reviews, case series, case reports, or animal studies; (III) participants who received diagnostic surgery for definite diagnosis (e.g., endoscopy); (IV) intervention, including moxibustion combined with other traditional therapies (e.g., acupuncture, retention enema with Chinese herbal medicine, and acupoint massage); and (V) studies with insufficient outcome data or unsuitable for analysis.

\section{Data extraction and quality assessment}

The two reviewers (Y Bian and L Yang) extracted the relevant data independently according to a predefined form. The characteristics of the included studies were author information, date of publication, participant characteristics, sample size, interventions, outcomes, and results. A consensus was reached through a discussion with the third reviewer $(\mathrm{Z} \mathrm{Li})$ in case of any discrepancies. The author was contacted to obtain the relevant data if the information was inadequate. The primary effectiveness outcomes assessed were the time to first flatus, the time to bowel sound recovery, and the time to first defecation; the secondary effectiveness outcome was the duration time of abdominal distention. The safety outcomes were the adverse events including any complications caused by moxibustion.

Cochrane's risk of bias tool was used to assess the methodological quality of RCTs (version 5.1.0) (21). The seven items followed a random sequence generation (selection bias), allocation concealment (selection bias), blinding of outcome assessment (selection bias), blinding of participants and personnel (performance bias), incomplete outcome data (attrition bias), selective reporting (reporting bias), and other biases. Each research result was judged as "low" for low-degree bias, "high" for high-degree bias, and "unclear" for uncertain bias conditions. Quality of reporting was performed using the Consolidated Standards of Reporting Trials (CONSORT) 2010 (available from http://www.consort-statement.org/) and STandards for Reporting Interventions in Clinical Trials of Moxibustion (STRICTOM) (22) on full-texts. STRICTOM is developed based on the CONSORT, a statement for RCTs, and Standards for Reporting Interventions in Clinical Trials of Acupuncture (STRICTA) (available from http://www. stricta.info/), a wide guideline for RCTs of acupuncture. Each item of the statements was judged as "Yes" for adequately reported, and "NO" for not adequately reported. Two review authors (Y Bian and L Yang) crossverified the methodological and reporting quality of the eligible studies, respectively. Disagreements were resolved through a discussion with a third review author $(\mathrm{Z} \mathrm{Li})$ and consensus.

\section{Statistical analysis}

Revman 5.2.0 software (available from the website for free: http://www.ccims.net/revman/download) was used for data analyses. For continuous outcomes of moxibustion, the mean difference (MD) with $95 \%$ confidence interval (CI) was used to calculate the effect size. Before merging the statistics, all studies were tested for heterogeneity using the chi-square and $\mathrm{I}^{2}$ tests. Forest plots were constructed for each outcome. The fixed-effect model was used if $\mathrm{P}>0.1$ and $\mathrm{I}^{2}<50 \%$, which indicated homogeneity. Otherwise, a random-effect model was applied for the analysis (23). Subgroup analysis was presented based on the pre-specified study-level characteristics (e.g., type of surgery, type of intervention, and type of comparators). Besides, Egger tests were generated to examine the publication bias, and the trim-and-fill computation was used to estimate the effect of 


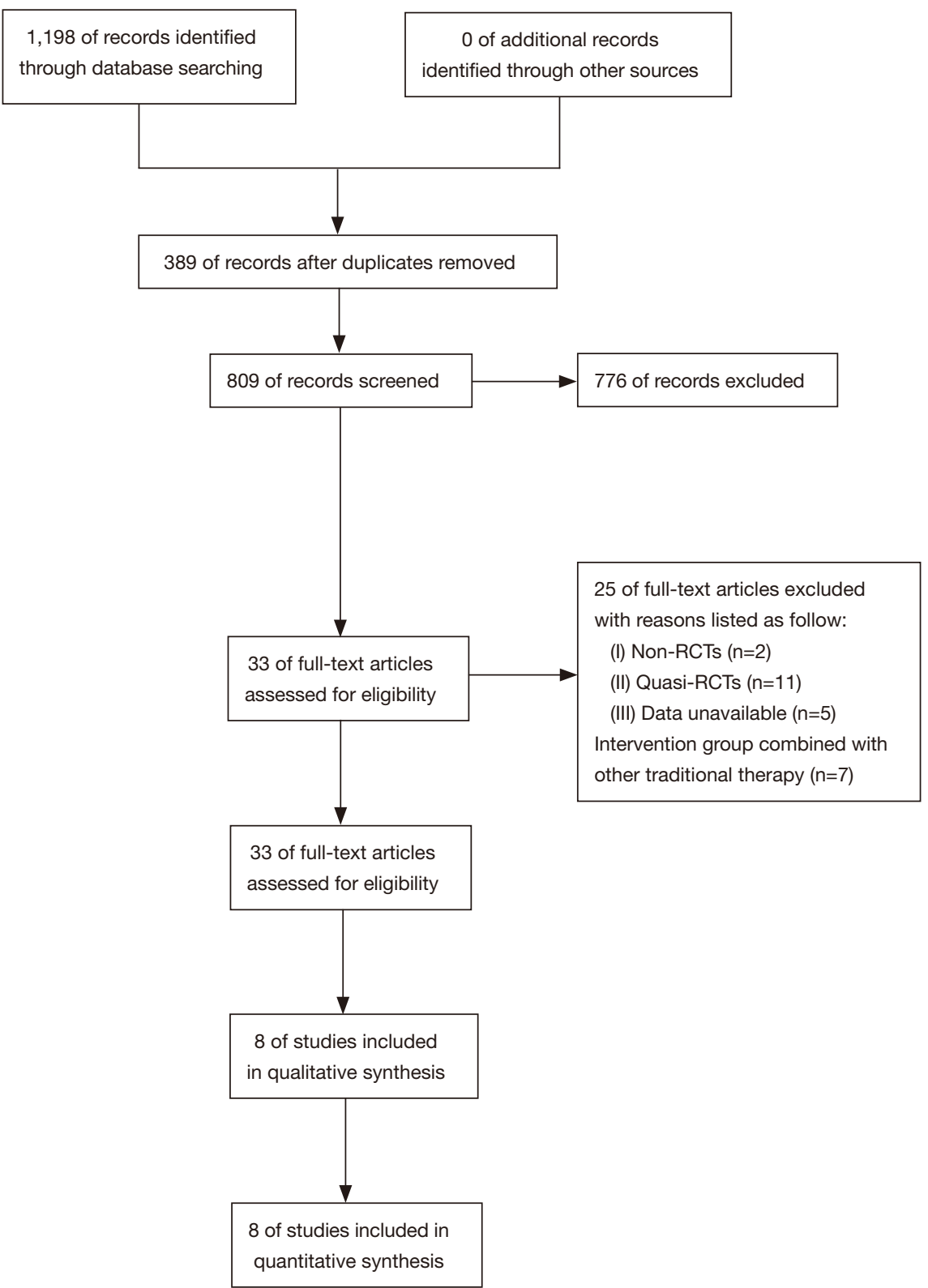

Figure 1 Flowchart of the trial selection process.

publication bias on the interpretation of the results (24).

\section{Results}

\section{Study selection}

Totally, 1,198 relevant articles were identified, in which 389 duplicate records were excluded. The remaining 809 studies were selected based on their titles and/or abstracts. A total of 776 studies were removed according to the inclusion criteria, leaving 33 full-text publications for further screening. Finally, eight RCTs (25-32) were included in this review, all of which were published in Chinese. Figure 1 shows the entire process of trial selection.

\section{Study characteristics}

The characteristics of the included trials are presented in Table 1. A total of 693 abdominal postoperative participants (345 in the intervention group and 348 in the controls) were 


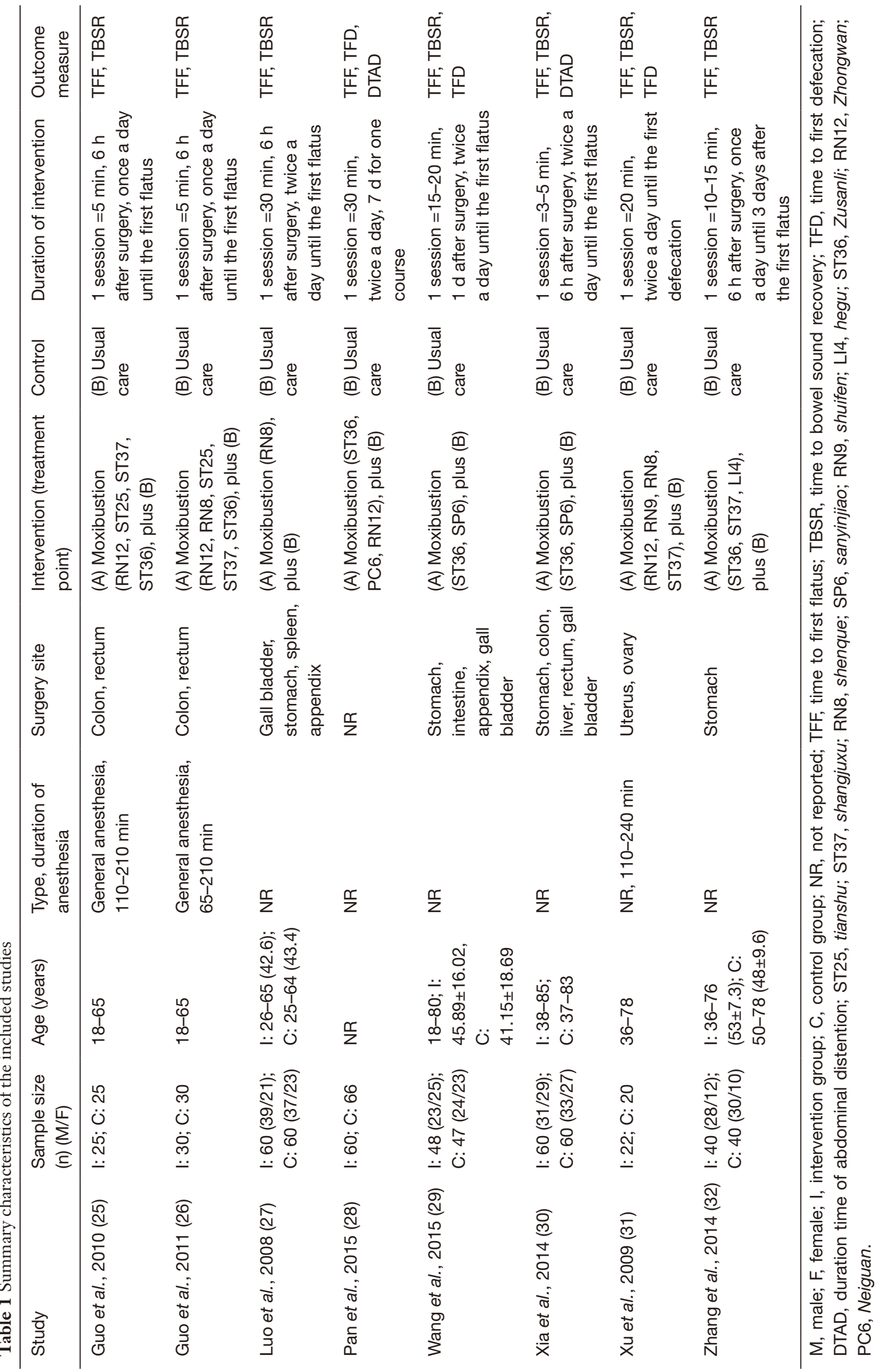




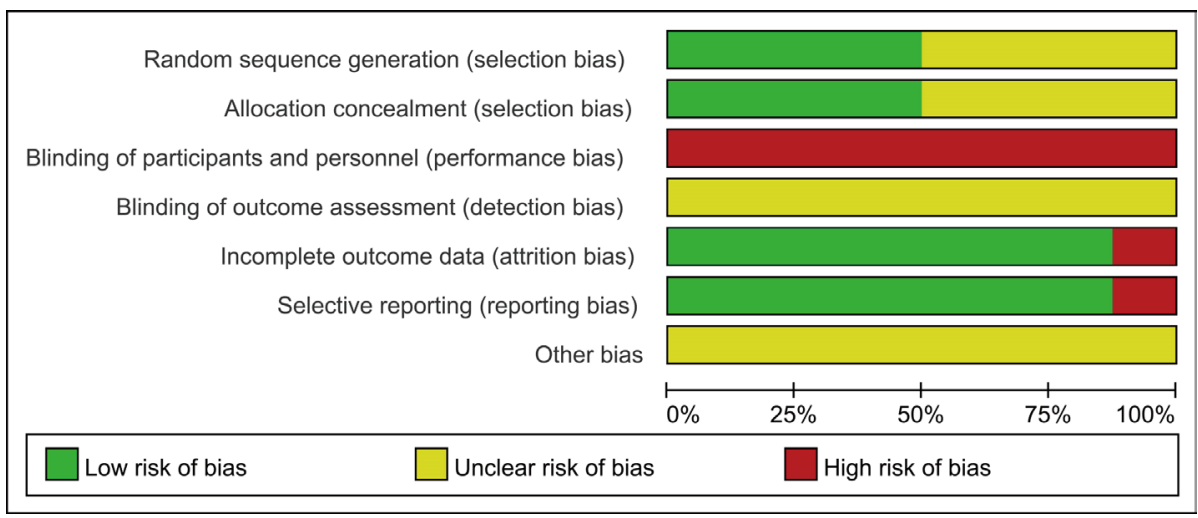

Figure 2 Risk of bias graph.

included.

The experimental interventions of all studies (25-32) used the moxibustion combined with usual care. The controls were usual care, including fasting, gastrointestinal decompression, parenteral nutrition support, and postoperative early mobilization. All studies reported the time to first flatus, seven studies (25-27,29-32) reported the time to bowel sound recovery with clear reporting standards, three studies $(28,29,31)$ reported the time to first defecation, and two studies $(28,30)$ reported the duration time to abdominal distention.

\section{Risk of bias assessment}

Although all studies mentioned "random allocation", only four studies $(27,29,30,32)$ reported appropriate methods of sequence generation for the randomization. The remaining studies $(25,26,28,31)$ did not describe the methods of sequence generation. None of the studies stated allocation concealment and dropout/withdrawal or mentioned blinding of outcome assessors. And none of the studies performed blinding to participants and personnel. This approach might be considered as a high risk of bias. The Cochrane risk of bias is presented in Figures 2,3.

\section{Reporting quality}

All RCTs were appraised based on the 25 standards of the CONSORT statement. In general, the included studies have poor reporting quality. All eligible studies mentioned demographic and clinical baseline characteristics. And most studies reported complete scientific background, intervention, statistical methods, and definition of the pre-specified primary outcome measures. However, the description of trial design, sample size estimate, methods of random allocation, concealment and blinding, trial limitations, and protocol registering were not fully reported in all included studies. The main detailed results based on CONSORT are listed in Table S1.

All RCTs were also assessed based on the 7 items and 16 sub-items of the STRICTOM. Two items (moxibustion rationale about the type of moxibustion, reasoning for choosing, and treatment regimen about the number, frequency, and duration of moxibustion corresponding with STRICTOM 1a, 1b, and 3) were well-stated in all studies. And all studies mentioned details of moxibustion including names of acupoints, and the time per acupoint. Most studies (25-27,29-31) reported detailed features, procedures, or techniques for moxibustion intervention, as well as control treatment in detail. However, none of the included studies stated the background of the practitioner, information/ explanations to patients, and reasoning for choosing the control treatment. In addition, patient posture, treatment environment, and any precaution measures were not reported in any studies. The detailed findings based on STRICTOM are presented in Table S2.

\section{Meta-analysis}

\section{Time to first flatus}

All studies reported the time to first flatus, and a randomeffects model was used. The meta-analysis showed that moxibustion combined with usual care had statistically significant effects on shortening the time to first flatus than usual care alone [MD $-15.15 \mathrm{~h}, 95 \% \mathrm{CI}:-19.14$ to $-11.15,8$ studies, $\mathrm{I}^{2}=85 \%, \mathrm{P}<0.00001$, random effects 


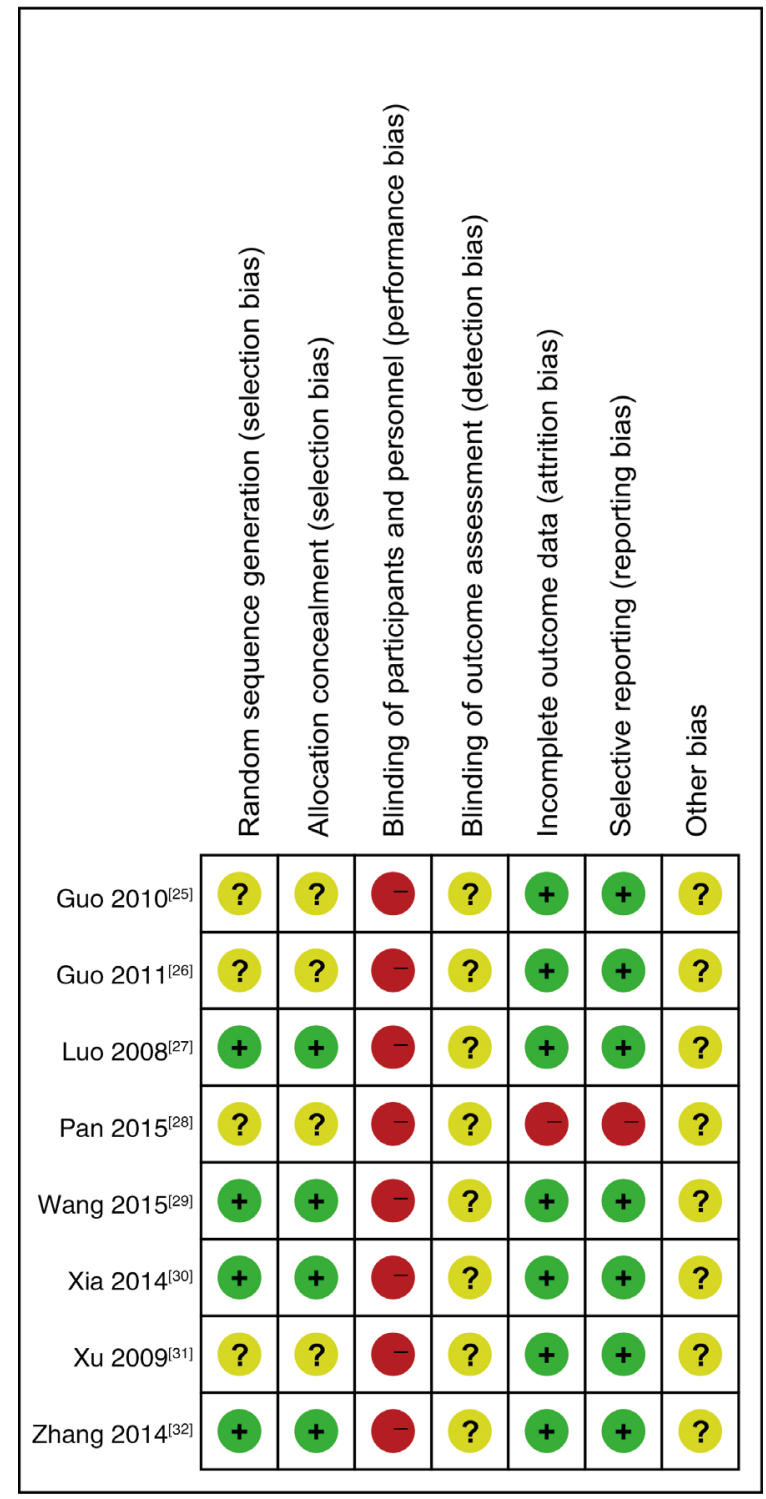

Figure 3 Risk of bias summary.

model (REM)]. The forest plots of the time to first flatus are shown in Figure 4. Excluding two studies $(28,32)$, the remaining studies were used for sensitivity analysis, and the heterogeneity disappeared. A fixed-effect model was used for further analysis, which showed that the time to first flatus in the intervention group was still shorter than the time in the controls. Statistical heterogeneity was found among the remaining six studies (25-27,29-31) [MD -11.31 h, $95 \%$ CI: -12.84 to $-9.78,6$ studies, $I^{2}=11 \%, P=0.35$, fixed effects model (FEM); Figure 5].

Time to bowel sound recovery

Seven studies $(25-27,29-32)$ reported the time to bowel sound recovery and a fixed effect model was used. The meta-analysis suggested that moxibustion combined with usual care had statistically significant effects on shortening the time to bowel sound recovery than usual care alone (MD -10.35 h, 95\% CI: -11.65 to $-9.06,7$ studies, $\mathrm{I}^{2}=0 \%$, $\mathrm{P}=0.91$, FEM; Figure 6A).

\section{Time to first defecation}

Three studies $(28,29,31)$ reported the time to first defecation and a fixed-effect model was utilized. The result suggested that moxibustion combined with usual care showed better effects on reducing the time to first defecation when compared to the usual care alone (MD -18.94 h, $95 \%$ CI: -24.53 to $-13.36,3$ studies, $\mathrm{I}^{2}=45 \%$, $\mathrm{P}=0.16$, FEM; Figure 6B).

\section{Duration time of abdominal distention}

Two studies $(28,30)$ reported the duration of abdominal distention, and a fixed-effect model was employed. The meta-analysis showed that moxibustion combined with usual care had better effects on decreasing the duration time of abdominal distention in comparison with the usual care alone (MD -11.7 h, 95\% CI: -15.32 to $-8.09,3$ studies, $\mathrm{I}^{2}=0 \%, \mathrm{P}=0.70$, FEM; Figure $\left.6 \mathrm{C}\right)$.

\section{Safety outcomes}

No study reported adverse events.

\section{Publication bias}

We assessed the possible publication bias using Egger tests, and defined significant publication bias as a $\mathrm{P}$ value $<0.1$. The results of Egger tests showed $\mathrm{P}=0.180$ for the time to first flatus and $\mathrm{P}=0.329$ for the time to first defecation when compared with the controls, indicating no potential publication bias in the selected studies. In this analysis, there was publication bias in the time to bowel sound recovery $(\mathrm{P}=0.053)$. However, further analysis with the trim-and-fill test indicated that this publication bias did not affect the estimates (i.e., no trimming done because data were unchanged). 


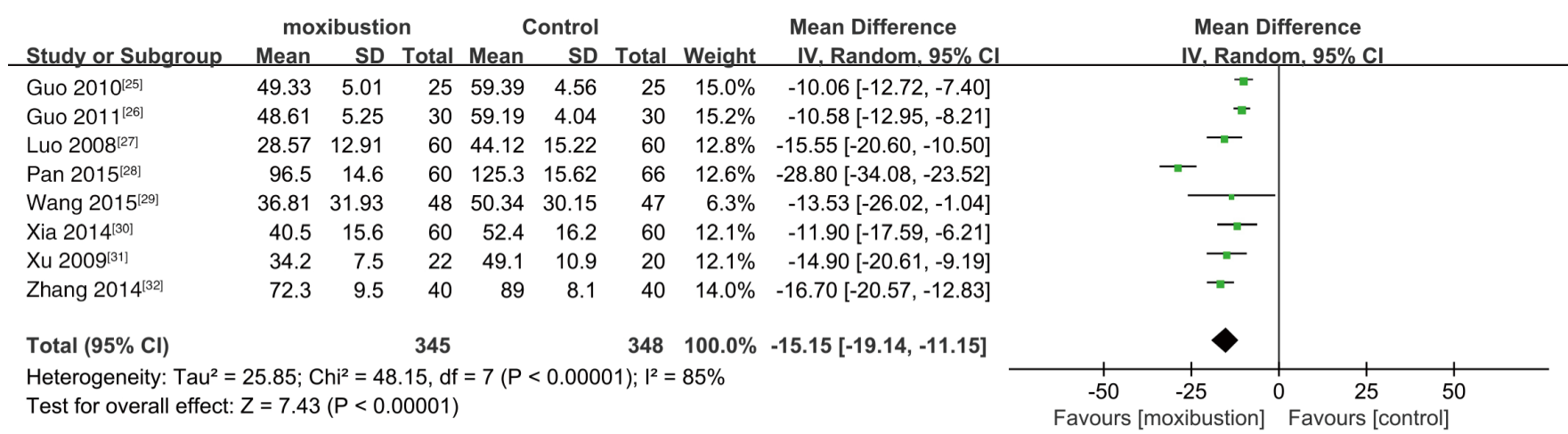

Figure 4 Forest plots of time to first flatus.

\begin{tabular}{lrrrrrrrrrr} 
& \multicolumn{3}{c}{ Moxibustion } & \multicolumn{3}{c}{ Control } & & Mean Difference & Mean Difference \\
Study or Subgroup & Mean & SD & Total & Mean & SD & Total & Weight & IV. Fixed, 95\% Cl \\
\hline Guo 2010. Fixed, 95\% CI
\end{tabular}

Figure 5 Sensitivity analysis of time to first flatus.

\section{Discussion}

EPSBO is defined as "epigastric pain," "qi stagnancy," "intestinal mass," and "accumulation" in TCM theory. It is a common condition after abdominal surgery. EPSBO is caused by viscera dysfunction, intestinal obstruction, $q i$ stagnation, and blood stasis, which is called "hindering pain." Meanwhile, it is also caused by the consumption of $q i$ and blood, the nutritional deficiency of the viscera, which is also called "deficiency pain." Danxi Zhu, a traditional Chinese physician, suggested that the blood runs through the blood vessels smoothly when it's warm. Conversely, the blood will be blocked when it's cold. It's reported that all diseases caused by the stagnation of $q i$ and blood can be treated with moxibustion (33).

Moxibustion therapy is an integral part of TCM, which has been used to treat and prevent diseases for more than 2,500 years. It is less well known in western countries than acupuncture due to the lack of modern medical evidence. Moxibustion is a traditional therapeutic remedy that is performed to obtain heat irritation by burning crushed dry moxa near or on the skin at certain acupoints. This therapy warms the interior and dissipates the cold, regulates $q i$ and resolves stasis, softens and dissolves mass, resuscitates yang, and warms the meridians. Modern studies $(34,35)$ found that moxibustion can obtain excellent lasting effects on regulating gastrointestinal motility and promoting gastrointestinal function recovery, which is consistent with our study.

The review of 8 RCTs (693 participants) evaluated the gastrointestinal function of moxibustion on preventing EPSBO. Moxibustion combined with usual care could effectively shorten the time to first flatus, the time to bowel sound recovery, and the time to first defecation. Meanwhile, moxibustion could shorten the duration time to abdominal distention than usual care alone, suggesting that moxibustion may improve the recovery effects of gastrointestinal function and have beneficial effects on preventing EPSBO.

Although the intervention of the studies was about moxibustion, the selection of the moxibustion acupoints was different. The main points were ST36 (6 articles), ST37 (4 articles), RN12 (4 articles), RN8 (3 articles), and ST25 (2 articles). ST36 is located on the stomach meridian. It can 


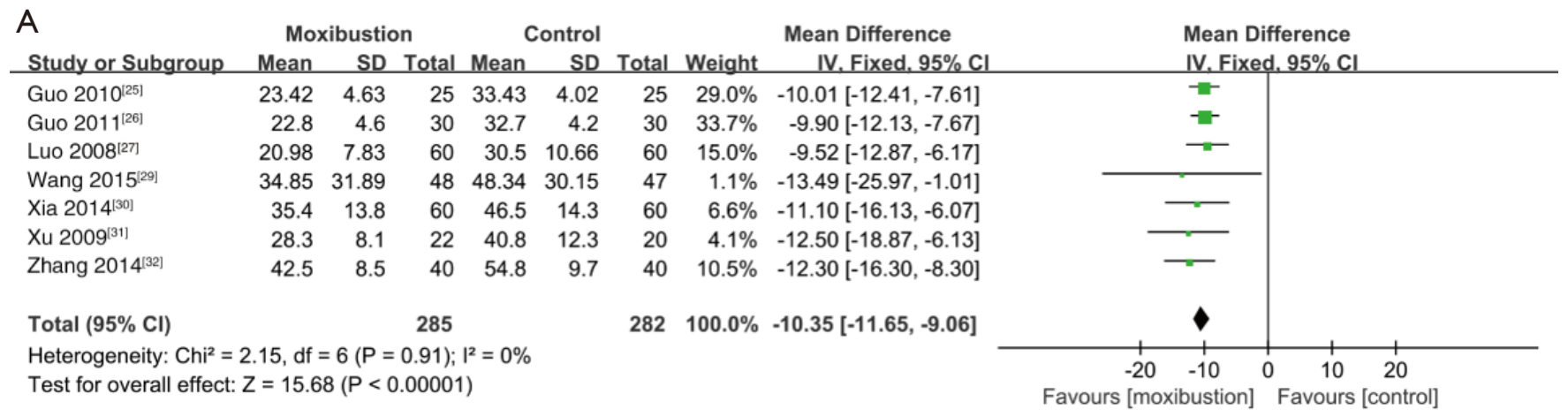

B

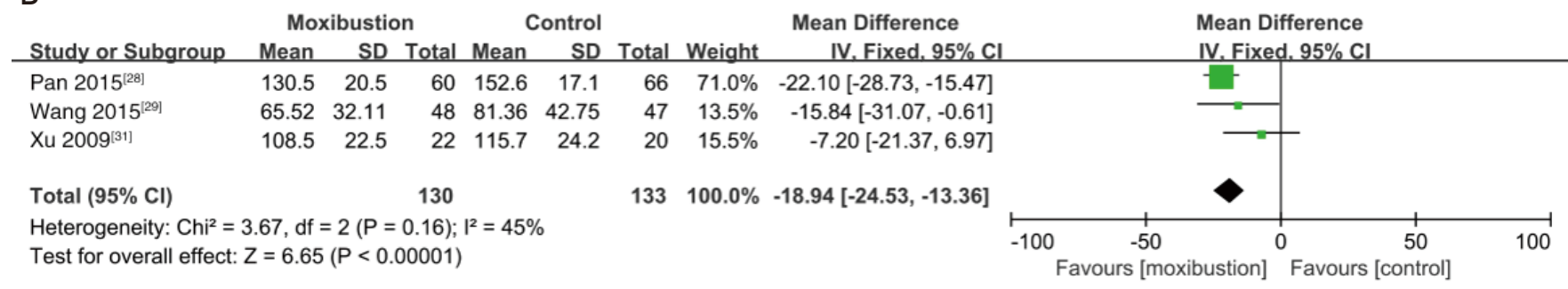

C

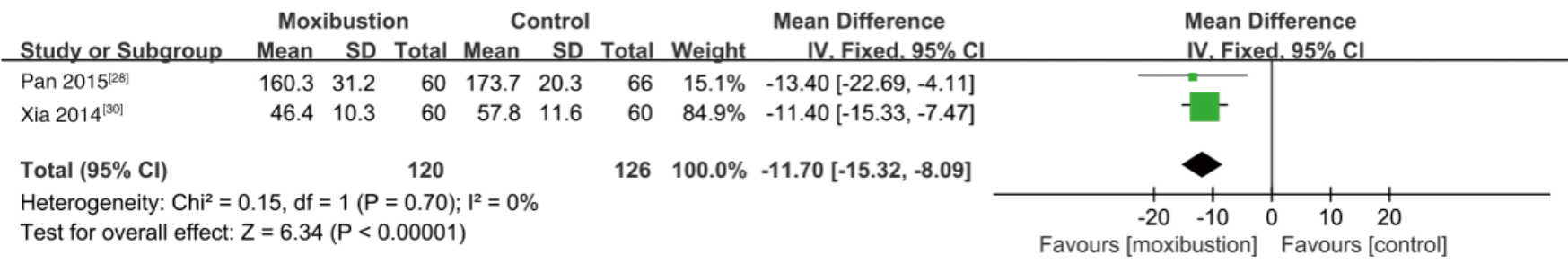

Figure 6 Forest plots within two groups. (A) Time to bowel sound recovery; (B) time to first defecation; (C) duration time of abdominal distention.

adjust the intestine and stomach, harmonize $q i$ and blood, and calm the rising of $q i$ in the stomach, thereby promoting gastrointestinal function. RN12 is an intersecting acupoint of the ren channel, small intestine meridian, triple energizer meridian, and stomach channel of foot-yangming. Moxibustion on RN12 can harmonize meridians and collaterals of the intestine and stomach. ST37 is the lower confluent acupoint of large and small intestines with the function of regulating the intestine, promoting the flow of $q i$, and removing $q i$ stagnation. $\mathrm{RN} 8$ is an acupoint of ren meridian that smoothens the $q i$ of the intestine and stomach, regulates yin-yang and qi-blood, promotes gastrointestinal functions, and alleviates abdomen distention. ST25 is the front $m u$ acupoint of the large intestine that can adjust the functions of zang-fu and regulate the flow of $q i$ to activate stagnancy. Moxibustion on the above acupoints has warm stimulating effects to run $q i$-blood and meridian, thereby recovering gastrointestinal function.

This study was the first review about moxibustion for gastrointestinal function recovery in preventing EPSBO. All eligible studies were appraised by Cochrane's risk of bias tool for methodological quality, and assessed by the CONSORT and STRICTOM checklists for reporting quality, respectively. Thus, certain limitations can still be observed.

First, significant heterogeneity of the time to first flatus was observed. This could be explained by the clinical heterogeneity. The outcome of the first flatus, a subjective indicator, was highly dependent on the participant's selfreporting that is difficult to measure with an objective assessment tool. When assessing the outcomes, the clinicians could not rule out the subjective factors and individual differences of the participants. It may eventually cause high heterogeneity. The other subjective outcomes (e.g., 
abdominal distention or first defecation) were also likely to have the same problem. These factors might influence the credibility of the results to a certain extent. Thus, objective assessment methods are required for future study of EPSBO prevention. Additionally, based on the CONSORT checklist and Cochrane's risk of bias, most studies did not report the methods on how to generate a random sequence. The unclear or less rigorous "randomization" may due to insufficient reporting of generation methods of allocation sequence, allocation concealment, and blinding. It may also influence internal validity and cause the overestimation of the actual therapeutic effect, which might cause selection bias. Because of the specificity of moxibustion therapy, it is hard to perform blinding methods and allocation concealment to participants and personnel. Furthermore, the patient can easily distinguish the sham moxibustion from the real one. That is why all included studies in our review used usual care as a control rather than sham moxibustion. However, a kind of sham moxa device as placebo made it possible to conduct randomized doubleblind, placebo-controlled clinical trials of moxibustion (36). Due to the lack of double-blind control, moxibustion can be easier to achieve a beneficial effect than controls. Hence, more rigorous RCTs with adequate allocation concealment, double-blinding methods, and using sham moxibustion as a placebo are needed to evaluate the true effect of moxibustion in enhancing gastrointestinal function in preventing EBPSO. Moreover, future studies with sample size estimates and adverse events in detail are also recommended.

Second, concerning the STRICTOM statement, none of the studies reported the patient's posture, treatment environment, and background of the treatment providers. The first two aspects are very important external factors that affect the whole process of moxibustion. Because the details of the patient's posture and treatment environment determine whether the results can be repeated. The background of the treatment providers in detail is one of the preconditions of moxibustion procedures to reach standardization and normalization. Any differences regarding qualification or affiliation of practitioners, experience in moxibustion practice may influence the therapeutic effect of moxibustion directly. Moreover, the effect of moxibustion on gastrointestinal function is also associated with details of moxibustion, e.g., the type of moxibustion, the selection of acupoints, the frequency of treatment session, and responses sought. Although the studies in our review had mentioned the above details, the various kinds of acupoints selected and the intensity of stimulation sought are not equivalent among the studies. The diversity of factors will lead to the incomparability of the outcomes and a high risk of bias among studies. So we suggested that researchers should consider the guideline of STRICTOM to design more rigorous RCTs with high quality about moxibustion.

Third, no studies reported adverse events; thus, the safety of moxibustion on gastrointestinal function cannot be assessed because of insufficient evidence. Only one study (28) reported that three participants in the control group had eventual reoperation, whereas the remaining studies did not report the adverse events. If EPSBO cannot be resolved, when will the subsequent reoperation be needed? Hence, the duration of moxibustion therapy for recovering gastrointestinal function in preventing EPSBO needs to be further studied.

Fourth, all studies were conducted in China, which might cause language bias. Considering that moxibustion is also one of the most widely used medical technology in Korea and Japan. Further studies should include subjects from East Asian countries. Besides, all the studies were selected from the conference paper or academic thesis, and the negative trials might not be reported. Additional databases, including gray literature, should be considered to avoid publication bias.

Fifth, the sample size was relatively small for a country of 1.4 billion people, and the smallest one had 20 cases in the control group (31). To avoid false-positive conclusions, further study should require a large sample size for RCTs to provide high levels of evidence.

\section{Conclusions}

In this systematic review, moxibustion might have a beneficial effect on gastrointestinal function recovery in preventing EPSBO. However, the small sample size, high risk of bias, low methodological quality, and poor reporting quality among the included studies influenced the credibility of the positive findings. Future rigorous studies with high quality and large samples are warranted to support the clinical benefit of moxibustion therapy on gastrointestinal function. We also suggest that clinical investigators refer to the extension of the CONSORT and STRICTOM standards for clinical trials of moxibustion to standardize the quality of RCTs and improve research transparency. 


\section{Acknowledgments}

Funding: This work was supported by the National Natural Science Foundation of China (No. 81704084 and 81673982), the Natural Science Foundation of Nanjing University of Chinese Medicine (No.NZY81704084), the Priority Academic Program Development of Jiangsu Higher Education Institutions (PAPD), the Open Projects of the Discipline of Chinese Medicine of Nanjing University of Chinese Medicine Supported by the Subject of Academic priority discipline of Jiangsu Higher Education Institutions (No.ZYX03KF63), the advantages of nursing discipline project of Jiangsu province (2019YSHL005), and Qing Lan Project (No. 014000773/2018-00376).

\section{Footnote}

Reporting Checklist: The authors have completed the Preferred Reporting Items for Systematic Reviews and Meta-Analyses (PRISMA) checklist. Available at http:// dx.doi.org/10.21037/apm-20-1266

Conflicts of Interest: All authors have completed the ICMJE uniform disclosure form (available at http://dx.doi. org/10.21037/apm-20-1266). The authors have no conflicts of interest to declare.

Ethical Statement: The authors are accountable for all aspects of the work in ensuring that questions related to the accuracy or integrity of any part of the work are appropriately investigated and resolved.

Open Access Statement: This is an Open Access article distributed in accordance with the Creative Commons Attribution-NonCommercial-NoDerivs 4.0 International License (CC BY-NC-ND 4.0), which permits the noncommercial replication and distribution of the article with the strict proviso that no changes or edits are made and the original work is properly cited (including links to both the formal publication through the relevant DOI and the license). See: https://creativecommons.org/licenses/by-nc-nd/4.0/.

\section{References}

1. Ellozy SH, Harris MT, Bauer JJ, et al. Early postoperative small-bowel obstruction: a prospective evaluation in 242 consecutive abdominal operations. Dis Colon Rectum 2002,45:1214-7.
2. Schein M, Sajja SB, Yenumula PR. Early postoperative intestinal obstruction. Curr Surg 2002;59:289-95.

3. Ray NF, Denton WG, Thamer M, et al. Abdominal adhesiolysis: inpatient care and expenditures in the United States in 1994. J Am Coll Surg 1998;186:1-9.

4. Sajja SB, Schein M. Early postoperative small bowel obstruction. Br J Surg 2004;91:683-91.

5. Frykberg ER, Phillips JW. Obstruction of the small bowel in the early postoperative period. South Med J 1989,82:169-73.

6. Stewart RM, Page CP, Brender J, et al. The incidence and risk of early postoperative small bowel obstruction. A cohort study. Am J Surg 1987;154:643-7.

7. Quatromoni JC, Rosoff L Sr, Halls JM. Early postoperative small bowel obstruction. Ann Surg 1980;191:72-4.

8. Quan SH, Stearns MJ. Early postoperative intestinal obstruction and postoperative intestinal ileus. Dis Colon Rectum 1961;4:307-18.

9. Cheadle WG, Garr EE, Richardson JD. The importance of early diagnosis of small bowel obstruction. Am Surg 1988;54:565-9.

10. Pickleman J, Lee RM. The management of patients with suspected early postoperative small bowel obstruction. Ann Surg 1989;210:216-9.

11. Gersin KS, Ponsky JL, Fanelli RD. Enteroscopic treatment of early postoperative small bowel obstruction. Surg Endosc 2002;16:115-6.

12. Iyer S, Saunders WB, Stemkowski S. Economic burden of postoperative ileus associated with colectomy in the United States. J Manag Care Pharm 2009;15:485-94.

13. Delaney CP, Senagore AJ, Viscusi ER, et al. Postoperative upper and lower gastrointestinal recovery and gastrointestinal morbidity in patients undergoing bowel resection: pooled analysis of placebo data from 3 randomized controlled trials. Am J Surg 2006;191:315-9.

14. Nelson R, Tse B, Edwards S. Systematic review of prophylactic nasogastric decompression after abdominal operations. Br J Surg 2005;92:673-80.

15. Sands DR, Wexner SD. Nasogastric tubes and dietary advancement after laparoscopic and open colorectal surgery. Nutrition 1999;15:347-50.

16. Li LY. The development of moxibustion therapy in Song dynasty. Acup Clin J 2003;19:1-2.

17. Kou XR, Sun LM, Guo N, et al. Observations on the therapeutic effect of acupuncture on post-cholelithotomy gastrointestinal dysfunction. Shanghai J Acu Mox 2010;29:103-4.

18. Shi XM. Science of acupuncture and moxibustion. 2nd ed. 
Beijing: China Traditional Medicine Press, 2009.

19. Zhao JM, Lu JH, Yin XJ, et al. Comparison of electroacupuncture and moxibustion on brain-gut function in patients with diarrhea-predominant irritable bowel syndrome: A randomized controlled trial. Chin J Integr Med 2015,21:855-65.

20. Takayama S, Takashima S, Okajima J, et al. Development and clinical application of a precise temperature-control device as an alternate for conventional moxibustion therapy. Evid Based Complement Alternat Med 2012;2012:426829.

21. Higgins J, Green S. the Cochrane Collaboration. Cochrane handbook for systematic reviews of interventions. Version 5.1.0 2011. Available online: http://www.cochranehandbook.org

22. Cheng CW, Fu SF, Zhou QH, et al. Extending the CONSORT Statement to moxibustion. J Integr Med 2013;11:54-63.

23. Higgins JP, Thompson SG. Quantifying heterogeneity in a meta-analysis. Stat Med 2002;21:1539-58.

24. Sterne JA, Sutton AJ, Ioannidis JP, et al. Recommendations for examining and interpreting funnel plot asymmetry in meta-analyses of randomised controlled trials. BMJ 2011;343:d4002.

25. Guo LX, Ru HF, Fang R, et al. Effects of temperature sensitive acupoint acupuncture and moxibustion on the recovery of enterokinesia after intestinal laparoscopic operations. J Nurs Sci 2010;25:32-3.

26. Guo LX. Comparison on effect of different ways to promote intestinal peristalsis recovery for patients after accepting laparoscopic intestinal operation. Chin J Nurs Res 2011;25:2078-9.

27. Luo SJ, Yin JL. Effect of Moxibustion at Shenque (RN8) for Preventing Abdominal Distention after Operation. J
Jinggangshan Med Colg 2008;15:40-53.

28. Pan Q, Wu BQ, Bao J, et al. Moxibustion for Treating Early Postoperative Inflammatory Small Bowel Obstruction 60 cases. Chin J Trad Med Sci Technol 2015;22:98-9.

29. Wang JJ, Hu LZ, Bian XM, et al. Effect of Moxibustion at Zusanli (ST36) and Sanyinjiao (SP6) for promoting Gastrointestinal Function after Abdominal Operation Gastrointestinal Function after Abdominal Operation. Chin J Trad Med Sci Technol 2015;22:291-2.

30. Xia Y, Zhang CQ. Effect of Moxibustion at Zusanli (ST36) and Sanyinjiao (SP6) for Promoting Gastrointestinal Function after Abdominal Operation. Shanghai J Acumox J 2014;33:518-9.

31. Xu XJ, Zhang F, Liu DH, et al. Acupuncture and Moxibustion on Preventing Gastrointestinal Dysfunction after Gynecological Malignancies Operation. Jiangsu Med J 2009;35:1372-3.

32. Zhang YW, Li AY, Ye JY. Effect of Moxibustion on Recovery of Intestinal Peristalsis after Postoperative Gastric Cancer. Nurs Rehabil J 2014;13:795-6.

33. Zhu ZH. Methods of Danxi. Beijing: People's Medical Publishing House, 2005.

34. Shen GW, Zhao JS. Acupuncture and Moxibustion Regulation for Post-chemotherapy Gastric Motility. J Acupunct Tuina Sci 2011;9:362-6.

35. Bing L. Clinical Observation on Treatment of Mild Acute Pancreatitis with Moxibustion. Beijing: Beijing University of Chinese Medicine, 2016.

36. Zhao BX, Chen HY, Shen XY, et al. Can moxibustion, an ancient treatment modality, be evaluated in a double-blind randomized controlled trial? - a narrative review. J Integr Med 2014;12:131-4.
Cite this article as: Yang L, Li Z, Li W, Zeng L, Bian Y. Effects of moxibustion on gastrointestinal function recovery in preventing early postoperative small-bowel obstruction: a metaanalysis. Ann Palliat Med 2021;10(4):3988-3999. doi: 10.21037/apm20-1266 
Table S1 Reporting quality of RCTs based on CONSORT

\begin{tabular}{|c|c|c|c|c|c|c|c|c|c|c|}
\hline Section/topic & Item No & Checklist item & Guo 2010 & Guo 2011 & Luo 2008 & Pan 2015 & Wang 2015 & Xia 2014 & Xu 2009 & Zhang 2014 \\
\hline \multicolumn{11}{|l|}{ Title and abstract } \\
\hline & $1 \mathrm{a}$ & Identification as a randomized trial in the title & $\mathrm{N}$ & $\mathrm{N}$ & $\mathrm{N}$ & $\mathrm{N}$ & N & $\mathrm{N}$ & N & N \\
\hline & $1 b$ & $\begin{array}{l}\text { Structured summary of trial design, methods, results, and } \\
\text { conclusions (for specific guidance see CONSORT for abstracts) }\end{array}$ & Y & Y & Y & N & Y & Y & N & Y \\
\hline \multicolumn{11}{|l|}{ Introduction } \\
\hline \multirow{2}{*}{$\begin{array}{l}\text { Background and } \\
\text { objectives }\end{array}$} & $2 a$ & Scientific background and explanation of rationale & $\mathrm{Y}$ & $\mathrm{Y}$ & $\mathrm{Y}$ & $\mathrm{N}$ & $\mathrm{Y}$ & $\mathrm{Y}$ & N & $\mathrm{Y}$ \\
\hline & $2 b$ & Specific objectives or hypotheses & N & $\mathrm{N}$ & $\mathrm{N}$ & $\mathrm{N}$ & N & Y & N & N \\
\hline \multicolumn{11}{|l|}{ Methods } \\
\hline \multirow[t]{2}{*}{ Trial design } & 3a & $\begin{array}{l}\text { Description of trial design (such as parallel, factorial) including } \\
\text { allocation ratio }\end{array}$ & N & $\mathrm{N}$ & $\mathrm{N}$ & $\mathrm{N}$ & N & $\mathrm{N}$ & N & N \\
\hline & $3 b$ & $\begin{array}{l}\text { Important changes to methods after trial commencement (such as } \\
\text { eligibility criteria), with reasons }\end{array}$ & N & $\mathrm{N}$ & $\mathrm{N}$ & N & N & N & N & N \\
\hline \multirow[t]{2}{*}{ Participants } & $4 a$ & Eligibility criteria for participants & Y & Y & Y & Y & Y & Y & Y & N \\
\hline & $4 \mathrm{~b}$ & Settings and locations where the data were collected & Y & Y & Y & Y & Y & Y & Y & Y \\
\hline Interventions & 5 & $\begin{array}{l}\text { The interventions for each group with sufficient details to } \\
\text { allow replication, including how and when they were actually } \\
\text { administered }\end{array}$ & Y & Y & Y & Y & Y & Y & Y & Y \\
\hline \multirow[t]{2}{*}{ Outcomes } & $6 a$ & $\begin{array}{l}\text { Completely defined pre-specified primary and secondary outcome } \\
\text { measures, including how and when they were assessed }\end{array}$ & Y & Y & Y & Y & Y & Y & Y & Y \\
\hline & $6 b$ & $\begin{array}{l}\text { Any changes to trial outcomes after the trial commenced, with } \\
\text { reasons }\end{array}$ & $\mathrm{N}$ & $\mathrm{N}$ & $\mathrm{N}$ & N & $\mathrm{N}$ & N & N & N \\
\hline \multirow[t]{2}{*}{ Sample size } & $7 a$ & How sample size was determined & $\mathrm{N}$ & $\mathrm{N}$ & $\mathrm{N}$ & $\mathrm{N}$ & $\mathrm{N}$ & $\mathrm{N}$ & $\mathrm{N}$ & $\mathrm{N}$ \\
\hline & $7 \mathrm{~b}$ & $\begin{array}{l}\text { When applicable, explanation of any interim analyses and } \\
\text { stopping guidelines. }\end{array}$ & N & $\mathrm{N}$ & $\mathrm{N}$ & N & N & N & N & N \\
\hline \multicolumn{11}{|l|}{ Randomization } \\
\hline \multirow[t]{2}{*}{ Sequence generation } & $8 \mathrm{a}$ & Method used to generate the random allocation sequence & $\mathrm{N}$ & $\mathrm{N}$ & $\mathrm{Y}$ & $\mathrm{N}$ & $\mathrm{N}$ & $\mathrm{Y}$ & $\mathrm{N}$ & $\mathrm{Y}$ \\
\hline & $8 b$ & $\begin{array}{l}\text { Type of randomization; details of any restriction (such as blocking } \\
\text { and block size) }\end{array}$ & $\mathrm{N}$ & $\mathrm{N}$ & Y & $\mathrm{N}$ & N & Y & N & Y \\
\hline $\begin{array}{l}\text { Allocation } \\
\text { concealment } \\
\text { mechanism }\end{array}$ & 9 & $\begin{array}{l}\text { Mechanism used to implement the random allocation sequence } \\
\text { (such as sequentially numbered containers), describing any steps } \\
\text { taken to conceal the sequence until interventions were assigned }\end{array}$ & $\mathrm{N}$ & $\mathrm{N}$ & $\mathrm{N}$ & N & N & $\mathrm{N}$ & N & $\mathrm{N}$ \\
\hline Implementation & 10 & $\begin{array}{l}\text { Who generated the random allocation sequence, who enrolled } \\
\text { participants, and who assigned participants to interventions }\end{array}$ & N & $\mathrm{N}$ & $\mathrm{N}$ & $\mathrm{N}$ & N & $\mathrm{N}$ & N & $\mathrm{N}$ \\
\hline \multirow[t]{2}{*}{ Blinding } & $11 a$ & $\begin{array}{l}\text { If done, who was blinded after assignment to interventions (for } \\
\text { example, participants, care providers, those assessing outcomes) } \\
\text { and how }\end{array}$ & $\mathrm{N}$ & $\mathrm{N}$ & $\mathrm{N}$ & N & $\mathrm{N}$ & $\mathrm{N}$ & $\mathrm{N}$ & N \\
\hline & $11 b$ & If relevant, description of the similarity of interventions & $\mathrm{N}$ & $\mathrm{N}$ & $\mathrm{N}$ & N & N & N & N & N \\
\hline \multirow[t]{2}{*}{ Statistical methods } & $12 \mathrm{a}$ & $\begin{array}{l}\text { Statistical methods used to compare groups for primary and } \\
\text { secondary outcomes }\end{array}$ & Y & Y & Y & Y & Y & Y & Y & Y \\
\hline & $12 b$ & $\begin{array}{l}\text { Methods for additional analyses, such as subgroup analyses and } \\
\text { adjusted analyses }\end{array}$ & N & $\mathrm{N}$ & $\mathrm{N}$ & $\mathrm{N}$ & N & $\mathrm{N}$ & N & N \\
\hline \multicolumn{11}{|l|}{ Results } \\
\hline \multirow[t]{2}{*}{$\begin{array}{l}\text { Participant flow (a } \\
\text { diagram is strongly } \\
\text { recommended) }\end{array}$} & $13 a$ & $\begin{array}{l}\text { For each group, the numbers of participants who were randomly } \\
\text { assigned, received intended treatment, and were analysed for the } \\
\text { primary outcome }\end{array}$ & $\mathrm{N}$ & $\mathrm{N}$ & $\mathrm{N}$ & N & N & N & N & $\mathrm{N}$ \\
\hline & $13 b$ & $\begin{array}{l}\text { For each group, losses and exclusions after randomization, } \\
\text { together with reasons }\end{array}$ & N & $\mathrm{N}$ & $\mathrm{N}$ & $\mathrm{N}$ & N & $\mathrm{N}$ & N & $\mathrm{N}$ \\
\hline \multirow[t]{2}{*}{ Recruitment } & $14 a$ & Dates defining the periods of recruitment and follow-up & N & $\mathrm{N}$ & $\mathrm{N}$ & $\mathrm{N}$ & $\mathrm{N}$ & $\mathrm{N}$ & N & N \\
\hline & $14 b$ & Why the trial ended or was stopped & N & $\mathrm{N}$ & $\mathrm{N}$ & N & N & $\mathrm{N}$ & N & N \\
\hline Baseline data & 15 & $\begin{array}{l}\text { A table showing baseline demographic and clinical characteristics } \\
\text { for each group }\end{array}$ & Y & Y & Y & Y & Y & Y & Y & $\mathrm{Y}$ \\
\hline Numbers analysed & 16 & $\begin{array}{l}\text { For each group, number of participants (denominator) included in } \\
\text { each analysis and whether the analysis was by original assigned } \\
\text { groups }\end{array}$ & Y & Y & Y & Y & Y & Y & Y & $\mathrm{Y}$ \\
\hline \multirow[t]{2}{*}{$\begin{array}{l}\text { Outcomes and } \\
\text { estimation }\end{array}$} & $17 a$ & $\begin{array}{l}\text { For each primary and secondary outcome, results for each group, } \\
\text { and the estimated effect size and its precision (such as } 95 \% \mathrm{Cl} \text { ) }\end{array}$ & N & N & $\mathrm{N}$ & $\mathrm{N}$ & N & $N$ & N & $\mathrm{N}$ \\
\hline & $17 b$ & $\begin{array}{l}\text { For binary outcomes, presentation of both absolute and relative } \\
\text { effect sizes is recommended }\end{array}$ & $\mathrm{N}$ & $\mathrm{N}$ & $\mathrm{N}$ & N & N & $\mathrm{N}$ & N & $\mathrm{N}$ \\
\hline Ancillary analyses & 18 & $\begin{array}{l}\text { Results of any other analyses performed, including subgroup } \\
\text { analyses and adjusted analyses, distinguishing pre-specified from } \\
\text { exploratory }\end{array}$ & $\mathrm{N}$ & $\mathrm{N}$ & N & $\mathrm{N}$ & N & $N$ & N & $\mathrm{N}$ \\
\hline Harms & 19 & $\begin{array}{l}\text { All important harms or unintended effects in each group (for } \\
\text { specific guidance see CONSORT for harms) }\end{array}$ & $N$ & $\mathrm{~N}$ & $\mathrm{~N}$ & N & N & $N$ & N & N \\
\hline \multicolumn{11}{|l|}{ Discussion } \\
\hline Limitations & 20 & $\begin{array}{l}\text { Trial limitations, addressing sources of potential bias, imprecision, } \\
\text { and, if relevant, multiplicity of analyses }\end{array}$ & N & $\mathrm{N}$ & $\mathrm{N}$ & $\mathrm{N}$ & N & $\mathrm{N}$ & N & $N$ \\
\hline Generalizability & 21 & Generalizability (external validity, applicability) of the trial findings & N & $\mathrm{N}$ & $\mathrm{N}$ & N & N & N & N & N \\
\hline Interpretation & 22 & $\begin{array}{l}\text { Interpretation consistent with results, balancing benefits, and } \\
\text { harms, and considering other relevant evidence }\end{array}$ & N & $\mathrm{N}$ & $\mathrm{N}$ & $\mathrm{N}$ & $\mathrm{N}$ & $\mathrm{N}$ & N & N \\
\hline \multicolumn{11}{|l|}{ Other information } \\
\hline Registration & 23 & Registration number and name of trial registry & $\mathrm{N}$ & $\mathrm{N}$ & $\mathrm{N}$ & $\mathrm{N}$ & N & $\mathrm{N}$ & N & N \\
\hline Protocol & 24 & Where the full trial protocol can be accessed, if available & $\mathrm{N}$ & $\mathrm{N}$ & $\mathrm{N}$ & $\mathrm{N}$ & N & $\mathrm{N}$ & $\mathrm{N}$ & $N$ \\
\hline Funding & 25 & $\begin{array}{l}\text { Sources of funding and other support (such as supply of drugs), } \\
\text { role of funders }\end{array}$ & $\mathrm{N}$ & $N$ & $\mathrm{~N}$ & $N$ & $\mathrm{~N}$ & $\mathrm{~N}$ & $N$ & $N$ \\
\hline
\end{tabular}

CONSORT, consolidated standards of reporting trials; RCTs, randomized controlled trials; $\mathrm{Y}$, adequately reported; $\mathrm{N}$, not adequately reported 


\begin{tabular}{|c|c|c|c|c|c|c|c|c|c|}
\hline Item & Detail & Guo 2010 & Guo 2011 & Luo 2008 & Pan 2015 & $\begin{array}{l}\text { Wang } \\
2015\end{array}$ & Xia 2014 & Xu 2009 & $\begin{array}{l}\text { Zhang } \\
2014\end{array}$ \\
\hline \multirow[t]{3}{*}{$\begin{array}{l}\text { Moxibustion } \\
\text { rationale }\end{array}$} & $\begin{array}{l}\text { 1a) Type of moxibustion (direct moxibustion, indirect } \\
\text { moxibustion, heat-sensitive moxibustion, moxa } \\
\text { burner moxibustion, natural moxibustion) }\end{array}$ & Y & $\mathrm{Y}$ & $\mathrm{Y}$ & $\mathrm{Y}$ & Y & $\mathrm{Y}$ & $\mathrm{Y}$ & Y \\
\hline & $\begin{array}{l}\text { 1b) Reasoning for treatment provided, based } \\
\text { on historical context, literature sources, and/ } \\
\text { or consensus methods, with references where } \\
\text { appropriate }\end{array}$ & Y & $\mathrm{Y}$ & $\mathrm{Y}$ & $\mathrm{Y}$ & $\mathrm{Y}$ & $\mathrm{Y}$ & $\mathrm{Y}$ & $\mathrm{Y}$ \\
\hline & 1c) Extent to which treatment was varied & $\mathrm{N}$ & $\mathrm{N}$ & $\mathrm{N}$ & $\mathrm{N}$ & $\mathrm{N}$ & $\mathrm{N}$ & $\mathrm{N}$ & $\mathrm{N}$ \\
\hline \multirow[t]{6}{*}{$\begin{array}{l}\text { Details of } \\
\text { moxibustion }\end{array}$} & $\begin{array}{l}\text { 2a) Materials used for moxibustion (moxa floss, } \\
\text { moxa cone, moxa stick, herbal patches, and their } \\
\text { sizes and manufacturers) }\end{array}$ & $\mathrm{N}$ & $\mathrm{N}$ & $\mathrm{Y}$ & $\mathrm{N}$ & $\mathrm{Y}$ & Y & $\mathrm{N}$ & $\mathrm{N}$ \\
\hline & $\begin{array}{l}\text { 2b) Names of acupoints (or location if no standard } \\
\text { name) for moxibustion (uni/bilateral) }\end{array}$ & $\mathrm{Y}$ & $\mathrm{Y}$ & Y & Y & $\mathrm{Y}$ & Y & $\mathrm{Y}$ & $\mathrm{Y}$ \\
\hline & $\begin{array}{l}\text { 2c) Number of moxibustion units and/or moxibustion } \\
\text { time per point (mean and range where relevant) }\end{array}$ & Y & Y & $\mathrm{Y}$ & $\mathrm{Y}$ & Y & $\mathrm{Y}$ & $\mathrm{Y}$ & $\mathrm{Y}$ \\
\hline & $\begin{array}{l}\text { 2d) Procedure and technique for moxibustion } \\
\text { (direct/indirect, warming/sparrow-pecking } \\
\text { technique, warming needle, moxa box, heat- } \\
\text { sensitive moxibustion) }\end{array}$ & $\mathrm{Y}$ & $\mathrm{Y}$ & Y & $\mathrm{N}$ & Y & Y & $\mathrm{Y}$ & $\mathrm{N}$ \\
\hline & $\begin{array}{l}\text { 2e) Responses sought (warm feeling, skin reddening, } \\
\text { burning pain, heat-sensitization phenomenon) }\end{array}$ & Y & $\mathrm{Y}$ & $\mathrm{Y}$ & $\mathrm{N}$ & Y & $\mathrm{Y}$ & $\mathrm{Y}$ & $\mathrm{N}$ \\
\hline & 2f) Patient posture and treatment environment & $\mathrm{N}$ & $\mathrm{N}$ & $\mathrm{N}$ & $\mathrm{N}$ & $\mathrm{N}$ & $\mathrm{N}$ & $\mathrm{N}$ & $\mathrm{N}$ \\
\hline Treatment regimen & $\begin{array}{l}\text { 3) Number, frequency, and duration of treatment } \\
\text { sessions }\end{array}$ & $\mathrm{Y}$ & Y & Y & Y & Y & $\mathrm{Y}$ & Y & Y \\
\hline \multirow[t]{2}{*}{$\begin{array}{l}\text { Other components } \\
\text { of treatment }\end{array}$} & $\begin{array}{l}\text { 4a) Details of other interventions administered to the } \\
\text { moxibustion group (acupuncture, cupping, herbs, } \\
\text { exercises, lifestyle advice) }\end{array}$ & $\mathrm{N}$ & $\mathrm{N}$ & Y & $\mathrm{Y}$ & $\mathrm{N}$ & Y & $\mathrm{Y}$ & $\mathrm{Y}$ \\
\hline & $\begin{array}{l}\text { 4b) Setting and context of treatment protocol, and } \\
\text { information and explanation to patients }\end{array}$ & $\mathrm{N}$ & $\mathrm{N}$ & $\mathrm{N}$ & $\mathrm{N}$ & $\mathrm{N}$ & $\mathrm{N}$ & $\mathrm{N}$ & $\mathrm{N}$ \\
\hline $\begin{array}{l}\text { Treatment } \\
\text { provider } \\
\text { background }\end{array}$ & $\begin{array}{l}\text { 5) Description of treatment provider (qualification or } \\
\text { professional affiliation, years in moxibustion practice } \\
\text { and other relevant experience for professional, or } \\
\text { any special training in advance for layman) }\end{array}$ & $\mathrm{N}$ & $N$ & $\mathrm{~N}$ & $N$ & $\mathrm{~N}$ & $\mathrm{~N}$ & $\mathrm{~N}$ & $\mathrm{~N}$ \\
\hline \multirow[t]{2}{*}{$\begin{array}{l}\text { Control or } \\
\text { comparator } \\
\text { interventions }\end{array}$} & $\begin{array}{l}\text { 6a) Rationale for the control or comparator in the } \\
\text { context of the research question, with sources that } \\
\text { justify this choice }\end{array}$ & $N$ & $N$ & $\mathrm{~N}$ & $\mathrm{~N}$ & $\mathrm{~N}$ & $\mathrm{~N}$ & $\mathrm{~N}$ & $\mathrm{~N}$ \\
\hline & $\begin{array}{l}\text { 6b) Precise description of the control or comparator. } \\
\text { If another form of moxibustion or moxibustion-like } \\
\text { control is used, provide details as for Items } 1-3 \\
\text { above. }\end{array}$ & $\mathrm{N}$ & $\mathrm{N}$ & $Y$ & $Y$ & $\mathrm{~N}$ & $Y$ & $Y$ & $Y$ \\
\hline $\begin{array}{l}\text { Precaution } \\
\text { measures }\end{array}$ & $\begin{array}{l}\text { 7) Precise description of the precaution measures, if } \\
\text { any }\end{array}$ & $\mathrm{N}$ & $\mathrm{N}$ & $\mathrm{N}$ & $\mathrm{N}$ & $\mathrm{N}$ & $\mathrm{N}$ & $\mathrm{N}$ & $\mathrm{N}$ \\
\hline
\end{tabular}

STRICTOM, standards for reporting interventions in clinical trials of moxibustion; RCTs, randomized controlled trials; $\mathrm{Y}$, adequately reported; N, not adequately reported. 